\title{
Basic Directions in Development of Accounting and Analytical Support of Businessing Subject Management Under Conditions of Accounting Digitalization
}

\author{
Natalia Lazareva \\ Institute of International Programs \\ Saint-Petersburg University of Management Technologies \\ and Economics \\ Saint-Petersburg, Russia \\ nataly.lazarev.1972@mail.ru \\ Natalia Khakhonova \\ Faculty of Accounting and Economics \\ Rostov State University of Economics RSUE (RINH) \\ Rostov-on-Don, Russia \\ n_khakhonova@bk.ru
}

\author{
Irina Bogataya \\ Faculty of Accounting and Economics \\ Rostov State University of Economics RSUE (RINH) \\ Rostov-on-Don, Russia \\ bogatyy89@rambler.ru \\ Valeria Orobinskaya \\ Institute of Service, Tourism and Design (branch) \\ North Caucasus Federal University \\ Pyatigorsk, Russia \\ orobinskaya.val@yandex.ru
}

\begin{abstract}
This article discusses the problems of developing a methodology and methods of accounting and the formation of accounting and analytical support for the company's management under conditions of economic processes digitalization, consisting in the lack of terminology unity, the need for a systematic approach to the formation and interaction of accounting, analytical and control subsystems, the use of foreign experience in cloud technologies application. The ways to solve the exposed problems are identified. Existing approaches and individual points of view on determining the role, importance, and specifics of using modern technologies in accounting are considered. The authors disclose the principles of accounting and analytical management support functioning in digitalization and propose a system of fundamental principles for its formation. The main advantage of the study is the improvement of both the general methodology and the creation of a basis for the accounting, analysis and control methods development based on modern digital technologies that ensure the continuity of the tactical and strategic decisionmaking process and the timely adjustment of the organization development strategy for the long term, which ensures the effectiveness of management decisions taken by organizations leadership.
\end{abstract}

Keywords: accounting, accounting and analytical system, accounting digitalization, cloud technologies in accounting, single information space

\section{INTRODUCTION}

The current stage of development, taking place in the context of the economic entities business models digital transformation, can rightfully be called the era of global data structuring. In almost every country the task is to form a single information space (hereinafter - the SIS), where data formed within the framework of business entities accounting and analytical systems occupy an important place.
At present in Russia the following areas can be distinguished in the field of the SIS forming: 1) the SIS formation at the state level (in particular, the creation of a public service website Gosuslugi.ru in the financial sector, in the field of taxes and fees, etc.) 2) the SIS formation at the economic entities level [1].

Accounting as a science is directly related to the collection, processing and structuring of both financial and non-financial information. This science specializes in the formation of databases aimed at making managerial decisions both at the level of economic entities themselves (the aggregated information generated in the framework of accounting and economic systems supports management decision-making processes) and at the macro level.

The accountant acts as the accounting and analytical system architect, and the basic requirements for the formation of this system are determined by legislation in affect and top management requests. Modern accounting and analytical systems include not only financial accounting data, but also other modifications of economic information, such as: human resources accounting data, social accounting, etc. Modern accounting and analytical systems should provide information that allows managing the future and timely identifying strategic challenges. In practice, there has been a clear tendency towards global integration within the accounting and analytical system of not only various types of accounting data, but also the involvement of large amounts of external information by an accountant in order to form his professional judgment. Digital technologies offer great opportunities related to online accounting, as well as the big data targeted use. Accounting and analytical systems become integrated with a large number of different databases that, ultimately, allows providing the business entity with customer focus. External information becomes an important information source in reflecting the facts of economic life (for example, in the formation of estimated 
liabilities), and the creation of the SIS is one of the state tasks without which it is impossible to form a decisionmaking base at both the micro and macro levels.

Digital technologies implemented on appropriate platforms transfer accounting systems into the sphere of collective thinking, shift accounting and control functions into electronic format, and also open up new possibilities in the formation of an accountant professional judgment.

In the structuring information process, the problem of the formation of many services, information resources, platforms similar in functionality, but different in design and content (for example, SPARK, Kontur-Focus, Svetofor, etc.) arises.

According to the Future of Accountancy survey, 96\% of the accountant respondents expressed absolute confidence that by 2022 all or a substantial part of their work will be automated [1]. Béatrice Charles, the president of Toulouse Institute of professional accountants in Midi-Pyrénées believes that "tomorrow there will probably be $100 \%$ digitized accounting companies that will integrate information flows in a fully automated way [2]".

Since 1991, when the first version of the 1C platform and the first configuration based on it, 1C: Accounting, appeared in the Russian Federation, there has been a breakthrough in the accounting organization and maintenance. The $1 \mathrm{C}$ : Enterprise program writer demonstrated that the similar operations execution can be entrusted to the computer, and the accountant can be provided with more complex cases. Organizations using the 1C software product appreciated its capabilities, and over time, the program popularity grew so much that it began to be used not only in Russia but also abroad, in countries such as Belarus, Vietnam, Bulgaria, Kazakhstan, Kyrgyzstan, China, Latvia, Moldova, Ukraine, Poland and Germany [3]. Russia's accession to the WTO has significantly expanded the possibilities of international cooperation, opened new borders in the field of partnership and the potential for joint business activities. At the legislative level, Russian accounting is being closely aligned with international financial reporting standards; a large-scale transformation of technical solutions is underway. Therefore, it is necessary to constantly expand the horizons of accounting, analysis and control methods based on modern digital technologies, ensuring the continuity of the process of making tactical and strategic decisions that affect the organization development strategy for the future formulation, to study new legislative acts and reporting requirements, to master new software products, what is said in the work of E. V. Kuznetsova, I. N. Bogataya, N. N. Khakhonova and S. P. Katerinin "Methodology of Building up the Accounting and Analytical Management Support for Organizations in Russia" [4].

The development and improvement of mechanisms and tools for organizing and maintaining accounting are based on many factors. Among the most important, it is necessary to highlight the following:

- development and implementation of the new 14 Federal Accounting Standards and amendments to the current Accounting Regulations [5];

- approaching of Russian accounting to international standards;
- accelerated implementation of it-technologies in the organization and maintenance of accounting and financial analysis and the use of foreign experience;

- development and implementation of new platforms and technologies, along with the applied technologies (fully packaged, cloud and hybrid products, advanced applications);

- protection of information from viruses and unauthorized entry into databases (regulations for ensuring information security, taking into account the peculiarities of business processes, as well as system architecture).

Each area is a separate problem that should be considered in depth and in detail in accordance with the goals and objectives of accounting and analytical support for the adoption of tactical and strategic managerial decisions. That is why the essence and features of the implementation of the optimal scenario for the digital economy development in modern Russia, practical recommendations on monitoring and controlling the implementation of the digital economy optimizing in modern Russia are of great importance. In their works N.N. Khakhonova, E.N. Makarenko, T.V.Makarenko, I.A. Kislaya [6], as well as A.P. Sukhodolov, E.G. Popkova and T.N. Litvinova [7] pay attention to these areas.

The main problems in the development of accounting and analytical systems in the digitalization context are problems caused by the insufficient development of the regulations governing the activities of organizations in the digital economy and the reflection of the economic life facts in the accounting and analytical system of the organization under conditions of the Internet commerce use; problems related to insufficient infrastructure development (Internet access, software, e-business, accounting processes robotics); in some cases - the reluctance of managers and accountants to use new technologies, as well as problems associated with cyber threats.

\section{Methodology}

Currently, there is a rapid transition of business, accounting and control, analytical, payment systems into a virtual (digital) space. Virtualization is the process of creating a software (or virtual) presentation of something, for example, virtual applications, servers, storages, and networks. This is the only and most effective way to reduce IT infrastructure costs while improving efficiency and adaptability for companies of all sizes [8].

Modern accounting and analytical systems are fonmed using 4 promising technologies such as: data analytics (descriptive, diagnostic, predictive and prescriptive), artificial intelligence, machine learning, mobile applications, cloud accounting, and also blockchain.

Processing large amounts of accounting information data strengthens the role of accountants and leads to possible risks in the corporate reporting preparation. In this regard, research should be aimed at identifying technological paradoxes associated with big data and corporate reporting. The development of the accounting methodology in the context of economic processes digitalization should be of a qualitative nature and take an interpretive position, exploring the participants ideas about the phenomenon of 
big data and corporate reporting, as noted by Khaldoon AlHtaybat and Larisa von Alberti-Alhtaybat in their work "Big Data and corporate reporting: impacts and paradoxes" [9].

In particular, IBM offers more efficient use of its information assets for quicker adoption of more informed decisions with the help of scalable and reliable solutions, Software Defined Storage Solutions. At the same time, the problem of excess data can be turned into a competitive advantage using a storage infrastructure that supports hybrid multi-cloud and optimized for next generation applications. Organizations often have to deal with the cloud technology adoption, as it increases cost, complexity, and increases human resources. Well-known company VMware Cloud allows organizations to take advantage of the coordinated infrastructure and operations in their IT environment to accelerate stalled migration and application migration strategies without changes, with virtually no downtime. In VMware Cloud Foundation-based environments enterprises can use a hyper-converged infrastructure with economic advantages compared to traditional multi-level deployments. Now is the time to unlock operational savings, reduce complexity, and eliminate information silos. Hyperconverged Infrastructure (HCI) integrates computing, network and storage resources into a single system [8]. VMware is the de facto standard in enterprise virtualization [10].

According to Andy Booth and his work "What is the complexity of Big Data for management accountants?", by 2020 more than $20 \%$ of all data will be in the "cloud". Cloud data storage is an online storage model, where data is stored on numerous network-distributed servers that are provided to customers mainly by a third party. The key point used here is the phrase "Big Data". Andy Booth believes this is the single most serious challenge of all that management accounting has faced throughout the history of the profession. Finding connected "patterns" in cloudy Big Data, and then sifting them out of these "patterns" of relevant information will be the most important task for qualified accountants, who must do everything in their power to know the trends and developments in this area as best as possible [11]. This opinion is shared by such authors as M. Cao, R. Chychyla, T. Stewart [12], J. Kokina, D. Pachamanova, A. Corbett [13], Z. Xu, G. L. Frankwick and E. Ramirez [14].

\section{RESULTS}

A large information system on a company-wide basis should provide the necessary performance in terms of its application by a large number of users who use the same resources; therefore in such cases it is advisable to use application solutions "in cloud" using 1cFresh technology on the $1 \mathrm{C}$ platform. The $1 \mathrm{cFresh}$ technology is a modern toolkit for creating online services that provide users with work in application solutions on the $1 \mathrm{C}$ : Enterprise platform via the Internet (in the "cloud"). The feasibility of using the $1 \mathrm{cFresh}$ technology appears in cases where it is necessary to provide users with access to several similar application solutions. For example, a service provider that provides small businesses and entrepreneurs; holding company or government agency; educational institutions, where students must perform tests or laboratory work using applied solutions (Fig. 1).
Currently, accounting migration processes to the cloud include the following stages: zero (there is no financial application in the cloud), the first stage (one or several applications are added to the cloud, but there is no integration), the second stage (integration with some applications is possible), the third stage (full integration of applications with the cloud).

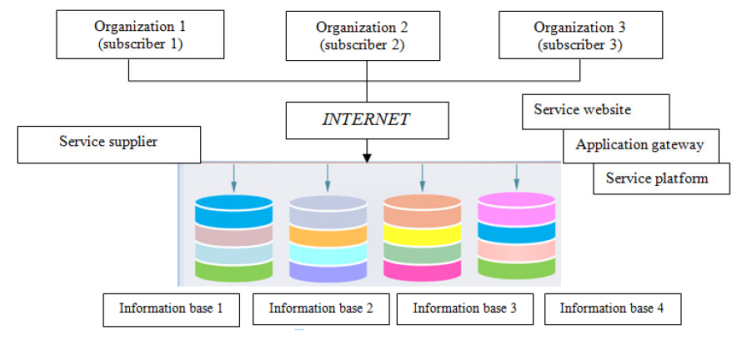

Fig. 1. Opportunities for providing users with access to similar application solutions

The lack of terminology consistency and systematic approach to the formation and interaction of accounting, analytical and control subsystems, conflicts in regulatory legal acts necessitate the development of these areas and the use of foreign experience. The issue is not so much about providing computer programs, enterprise-class cloud technologies for the private cloud and hybrid solutions to ensure efficient and rational work of financial and managerial accounting, but rather for harmonizing data at a global level, creating uniformity in terminology, which are tactical tasks to rise accounting and analytical systems to a new level [15].

Thus, in the methodology and methods applied in digital accounting, the following concepts are used: Applications, Cloud Economy, Cloud Accounting, information scalability, flexible hybrid cloud environment. There are several varieties of them in the cloud family (Figure 2).

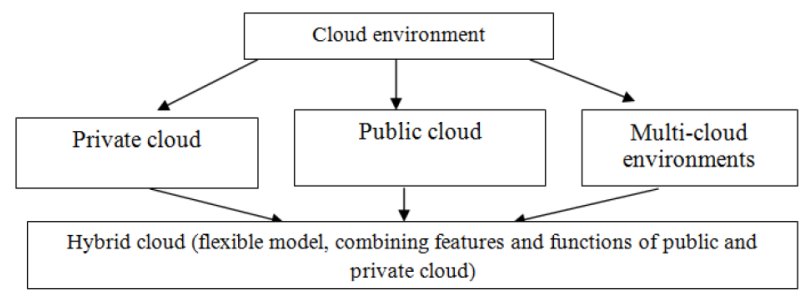

Fig. 2. Cloud environment model [4]

The cloud is a model that allows to scale sources according to your needs. The more users apply the system, the more sources will be attracted. Cloud education uses the invention of a perpetual, universally accessible, expandable computer network and uses it for electronic education from online classes at accredited universities to small training modules used by private companies [16].

Cloud services are built as a construction kit; they allow an accountant to design an accounting and analytical system from the proposed set of modules. Currently, there are following top online accounting programs in Russia: "My business", "Kontur", "Nebo", "1C" and "Bukhsoft".

Currently, there are the most popular cloud services, such as pCloud, MEGA, MediaFire, Box, Mail.Ru, Yandex.Disk, iCloud, Dropbox, OneDrive, Google Cloud Storage. To establish the possibility of their use in the 
formation and interaction of accounting, analytical and control subsystems, it is necessary to study their potential. Companies working in the field of virtualization and cloud computing (Citrix, Microsoft, VMware) offer cloud technologies for organizing accounting and analytical work in order to raise the software networks efficiency to a new level. With their help, you will have the opportunity to work and participate in joint projects regardless of your location. Citrix solutions provide easy and secure access to applications and data from any modern device [8]. For example, Citrix offers cloud-based technology for mobile work.

The use of foreign experience, including the application of software from leading companies in the development of enterprise-class IT-technologies for a private cloud and hybrid solutions, is one of the main strategic priorities that come to the following:

- ensuring an accelerated transition to cloud services that will lead to the possibility of creating a coordinated infrastructure and processes in a hybrid and public cloud;

- transformation of the network and security system (connecting and protecting applications anywhere);

- introduction of a digital workspace;

- ensuring the safety and convenience for the user on any device;

- development of storage architecture based on the use of a common hypervisor;

- use of network virtualization technology.

In the process of making tactical decisions, there is a need for timely adjustment of the organization development strategy for the future that is ensured by constant monitoring and testing of IT-systems for the possibility of applying (implementing, replacing) professional programs. The development and implementation of new platforms and technologies lead to the improvement of accounting and analytical support for the organizations management under conditions of economic processes digitalization.

\section{DISCUSSION}

Thus, the digital economy, on the one hand, opens up new prospects for improving accounting and analytical systems, and on the other hand poses a number of challenges. When creating an accounting and analytical system, it is necessary to take into account the specifics of new objects generated by digitalization (for example, cryptocurrencies); on the other hand, to generate data, it is necessary to develop a clear position regarding their structuring and integration with external information, as well as non-financial information based on using the capabilities of digital technologies, such as: cloud technologies, mobile applications, blockchain, etc.

Integration of various databases within the framework of the accounting and analytical system will solve the problems of information duplication, its redundancy, filtering and selection of the necessary information. It should be noted that the role of the prognostic function will increase within the framework of the accounting and analytical system. Accounting and analytical systems become strategically oriented and, when reporting, they actively attract information about the external environment [17].

\section{CONCLUSIONS}

Summing up, we come to several conclusions:

The evolution of accounting and analytical systems is associated with the use of modern electronic tools and digital platforms, involves the formation and exchange of data between process participants on-line that will require strengthening the prognostic function and the development of forward-looking accounting, which allows to combine accounting technologies with planning, budgeting, and forecasting technologies. The use of digital technologies helps to reduce routine labor when creating accounting information within the accounting and analytical system, increases the speed, accuracy and quality of data, reduces the risk of errors, and increases the level of control. The functions of accountants are changing accordingly; the most important ones, in the opinion of the International Federation of Accountants, should be "providing better decision support and not [focusing] on data collection and manual analysis", as well as managing risks associated with artificial intelligence by supporting effective management and internal control [18].

\section{References}

[1] Artificial intelligence in the view of professional accountants [Electronic resource]. Available at: https:/gaap.ru/news/155725/ (Accessed: 20.08.2019).

[2] Expert comptable: une profession révolutionnée par le numérique. [Electronic resource]. Available at: https://www.ladepeche.fr/article/2018/04/03/2772631-expert-

comptable-une-profession-revolutionnaire.html (Accessed: 20.08.2019).

[3] E. Nikitina, 1C at European markets. Infostart LLC, Published work no. 165969 [Electronic resource]. Available at: https://infostart.ru/public/165969/ (Accessed: 04.11.2019).

[4] E.V. Kuznetsova, I.N. Bogataya, N.N. Khakhonova, and S.P. Katerinin, Methodology of Building up the Accounting and Analytical Management Support for Organizations in Russia. European Research Studies, vol. XX, iss. 1, special issue, pp. 258269, 2017.

[5] Global changes in accounting: on corrections in 402-FZ and new FAS, "Aktiv" Financial Academy, 2019 [Electronic resource]. Available at: https://finacademy.net/ materials/article/izmeneniya-vbuhuchete (Accessed: 05.11.2019).

[6] N.N. Khakhonova, E.N. Makarenko, T.V. Makarenko and I.A. Kislaya, Models of Modern Information Economy: Conceptual Contradictions and Practical Examples. Emerald Publishing Limited. Howard House, Wagon Lane, Bingley BD16 1WA, UK, pp. 323$333,2018$.

[7] Models of Modern Information Economy: Conceptual Contradictions and Practical Examples. Stages of Information Economy's Formation Emerald Publishing Limited, Howard House, Wagon Lane, Bingley BD16 1WA, UK, pp. 37-46, 2018.

[8] Virtualization and cloud computing [Electronic resource]. Available at: https://linkas.ru/company/projects/itinfrastruktura/virtualizatsiya-i-oblachnye-vychisleniya/ (Accessed: 07.11.2019).

[9] K. Al-Htaybat and L.V. Alberti-Alhtaybat, "Big Data and corporate reporting: impacts and paradoxes. Accounting", Auditing \& Accountability Journal, 30 (4), pp. 850-873, 2017.

[10] A. Tugov, Public cloud based on VMware, 2018 [Electronic resource]. Available at: https://blog.selectel.ru/selectel-vmwarecloud/ (Accessed: 04.11.2019).

[11] "Booth Andy. What is the complexity of Big Data for management accountants?", GAAP.RU, Theory and practice of management accounting [Electronic resource]. Available at: 
https://gaap.ru/articles/V_chem_slozhnost_Bolshikh_dannykh_dlya bukhgalterov_v_oblasti_upravlencheskogo_ucheta/ ${ }^{-}$(Accessed: 06.11.2019)

[12] M. Cao, R. Chychyla, and T. Stewart, "Big Data Analytics in Financial Statement Audits", Accounting Horizons, 29 (2), pp. 423$429,2015$.

[13] J. Kokina, D. Pachamanova, and A. Corbett, "The role of data visualization and analytics in performance management: guiding entrepreneurial growth decisions", Journal of Accounting Education, 38 , pp. 50-62, 2017.

[14] Z. Xu, G.L. Frankwick, and E. Ramirez, "Effects of big data analytics and traditional marketing analytics on new product success: A knowledge fusion perspective", Journal of Business Research, 69 (5), pp. 1562-1566, 2016.

[15] N. Kuznetsov, N. Vovchenko, and T. Epifanova, "Development of innovative small-scale enterprises in conditions of institutional of the region's economy", Journal of Modern Competition, vol. 12, no. 2 (68)-3 (69), pp. 61-72, 2018.

[16] Blended learning in Russia, Dictionary: new learning technologies, 2019 [Electronic resource]. Available at: https://blendedlearning.pro/blended_learning_models/11-2/.

[17] L. Usenco and O.Kovaleva, "Methodological and institutional provisions on management accounting in higher educational establishments based on modular approach", Economics and management: theory and practice, Collection of scientific articles, Verlag SWG imex GmbH, Nürnberg, Deutschland, vol. 2, pp. 211318, 2014.

[18] Accounting Tech Trends to Watch for in 2019 [Electronic resource]. Available at: https://onlinemasters.ohio.edu/blog/3-accounting-techtrends-to-watch-for-in-2019/ (Accessed: 20.08.2019). 